\title{
Evaluation of Lipid Peroxidation under Immobilization Stress in Irradiated Animals in Experiment
}

\author{
Assem K. Okassova $^{1 *}$, Oralbek Z. Ilderbayev ${ }^{1}$, Akmaral Zh. Nursafina $^{1}$, Gulmira M. Zharmakhanova ${ }^{2}$, Bibigul B. Rakhimova ${ }^{3}$, \\ Yessilbaeva T. Bayan ${ }^{3}$, Dyussenbekova N. Bayan ${ }^{3}$ \\ ${ }^{1}$ Department of General Biology and Genomics, L.N. Gumilyov Eurasian National University, Nur-Sultan, Kazakhstan; \\ ${ }^{2} 2$ Department of Natural Science Disciplines, West Kazakhstan Marat Ospanov Medical University, Aktobe, Kazakhstan; \\ ${ }^{3}$ Department of Biomedicine, Karaganda Medical University, Karaganda, Kazakhstan
}

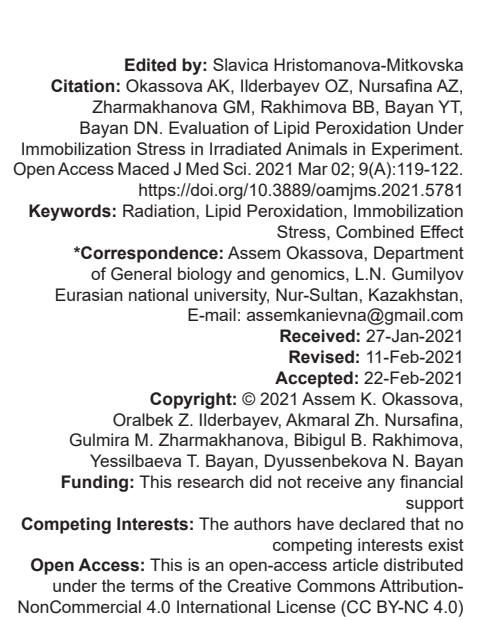

\section{Introduction}

For many years, the world community has been concerned with the problem of the consequences of radiation exposure on the human body. A wide range of possible variants of radiation effects on humans and biota determines the range of necessary pharmacological means of protecting the organism and populations. In the mechanisms of the formation of radioresistance, the leading role is assigned to the processes of lipid peroxidation (LPO) and the antioxidant (AO) system [1], [2], [3], [4].

One of the debatable issues is the question of the contribution of the dose and/or dose rate to the formation of the consequences of weak radiation effects [5], [6], [7]. An important factor in the biological effectiveness of exposure to low-intensity IS in small doses is the initial AO status in animal tissues as one of the main parameters of the LPO regulation system.

Maintaining a balance between the processes of free radical and peroxidation and the state of $\mathrm{AO}$ protection is one of the most common biochemical reactions occurring in the human body and ensuring its vital activity [8], [9], [10], [11], [12], [13]. However, the changes that occur in the body with the processes of LPO and the combined action of $\gamma$-radiation against the background of immobilization stress have been relatively little studied [12].

Despite the existence of various theories of the biological effect of small doses of ionizing radiation, most authors attach primary importance to DNA damage in the manifestation of the genetic effects of 
radiation [14], [15], [16]. In general, the patterns of the release of genetic disorders in the area of low doses are characterized by a pronounced nonlinearity and have a universal character, differing for different objects by the values of doses at which the nature of dependence changes and their sensitivity to external influences is determined [15], [17].

The study of the effect of such factors as radiation and immobilization stress on the body separately and in combination is relevant since the modern conditions of human habitation are characterized by high urbanization, physical inactivity, and a complex radioecological situation in a number of regions [4], [5], [18], [19].

\section{Materials and Methods}

He work was carried out on 40 male Wistar rats weighing 200-250 g and was divided into four groups: I-control ( $n=10)$; II-subjected to immobilization stress after $1 \mathrm{~h}$ ( $\mathrm{n}=10)$; III-exposed to gamma irradiation ( $n=10)$; and IV-tested combined effects (immobilization stress and gamma radiation) $(n=10)$. Rats from groups III and IV were exposed to radiation at a dose of 6 Gy once on a TERAGAM Co60 apparatus (Czech Republic).

Experiments on animals were carried out in accordance with the requirements of the Geneva Convention "International Guiding Principles for Biomedical Research Involving Animals" (Geneva, 1990). The animals were immobilized by placing them in special plastic cages-cases, limiting their movements for $6 \mathrm{~h}$ with a break of an hour's rest three times at room temperature. The animals were withdrawn from the experiment 1 hour after stress by decapitation against the background of light ether anesthesia.

Animals of groups III and IV were irradiated 30 days before the study on the TERAGAM Co60 radiotherapy device once at a dose of 6 Gy. The products of LPO in various organs and cells were determined in animals. For the study, lymphocytes were isolated from peripheral blood and homogenates were prepared from the liver, spleen, thymus, lymph nodes of the small intestine, and adrenal glands. The content of diene conjugates (DC) and malondialdehyde (MDA) was determined in them. The obtained results of the study were processed by the generally accepted methods of variation statistics with the calculation of Student's criteria [20].

\section{Results}

As studies have shown, under immobilization stress, the concentration of DC increases in peripheral blood lymphocytes from $0.21 \pm 0.02$ to $0.34 \pm 0.03$ $(p<0.05)$ and in the thymus from $0.44 \pm 0.03$ to $0.53 \pm$ $0.03(p<0.05)$ (Figure 1). After irradiation in animals, the level of DC in blood lymphocytes remains at an increased level $(p<0.05)$, and no changes were observed in the thymus. In experimental animals, after stress-radiation exposure, the concentration of DC in peripheral blood lymphocytes and thymus showed significant changes, the content of DC in lymphocytes was almost 2.1 times higher $(p<0.001)$, in the thymus, it was almost 3.7 times $(p<0.001)$ increased. The content of DC in immobilization animals in the liver and adrenal glands of the small intestine showed that an increase was noted in the liver from $0.64 \pm 0.05$ to $1.89 \pm 0.13(p<0.001)$, that is, by 2.9 times, and in the adrenal glands - from $1.24 \pm 0.08$ to $2.32 \pm 0.21$ $(p<0.01)$, approximately 1.9 times.

Please reference the figure in the text (Figure 1).

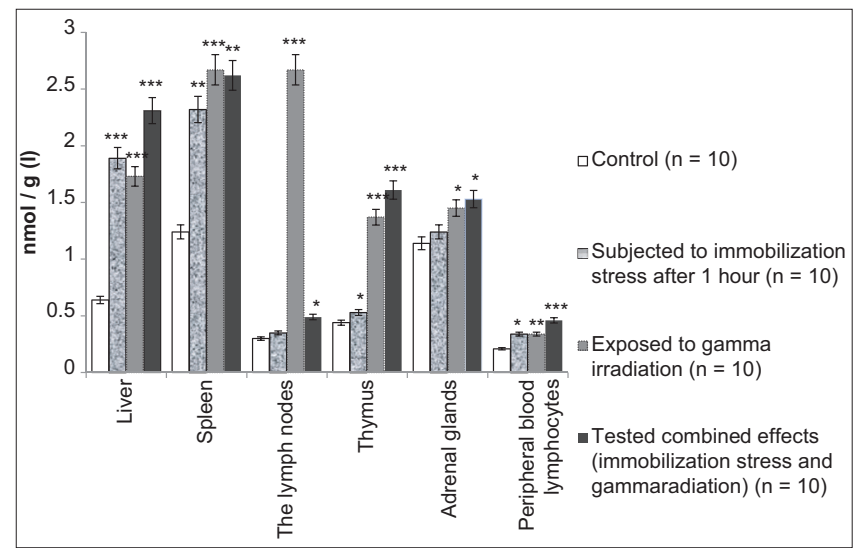

Figure 1: The content of $D C$ in various objects of research and series in the experiment. The different are statistically significant with the intact group: ${ }^{*} p<0.05,{ }^{* *} p<0.01,{ }^{* * *} p<0.001$

The concentration of DC in the lymph nodes of the small intestine in animals of group III, exposed to gamma irradiation, increased from $0.30 \pm 0.02$ to $2.67 \pm 0.20$, or 8.9 times $(p<0.001)$, and in group IV up to $0.49 \pm 0.13$ or 1.6 times $(p<0.05)$. In the liver homogenates of irradiated animals, a tendency to increase was noted, when, under the influence of a stress-radiation factor, the amount of DCs increased from $0.64 \pm 0.05$ to $2.31 \pm 0.27$ or 3.6 times $(p<0.001)$. In the second and third groups, no significant changes were observed on the part of the adrenal glands, and in the animals of group IV, an increase in the number of $D C$ by 1.3 times was noted $(p<0.05)$. On the part of the spleen, the level of DCs showed a tendency to increase, when, under the influence of a stress-radiation factor, the amount of DCs increased from $1.24 \pm 0.08$ to $2.62 \pm 0.29$, or 2.1 times $(p<0.01)$.

The results obtained indicate that when exposed to stress and stress-radiation factors, free radical oxidation is activated, possibly due to a decrease in the activity of $\mathrm{AO}$ enzymes in most of the studied organs in these series. After radiation exposure, a tendency toward an increase in the product of LPO was noted in all objects. As you know, the activation of LPO is based on 
excessive generation of reactive oxygen species, which exceeds the physiological capabilities of $\mathrm{AO}$ systems that occur after depletion of enzyme systems. And also a combination of these mechanisms in the case of the action of the radiation factor, which is determined, on the one hand, by the massive death of radiosensitive cells of the body and the loss of AOs, and, on the other hand, by the active generation of LPO initiators.

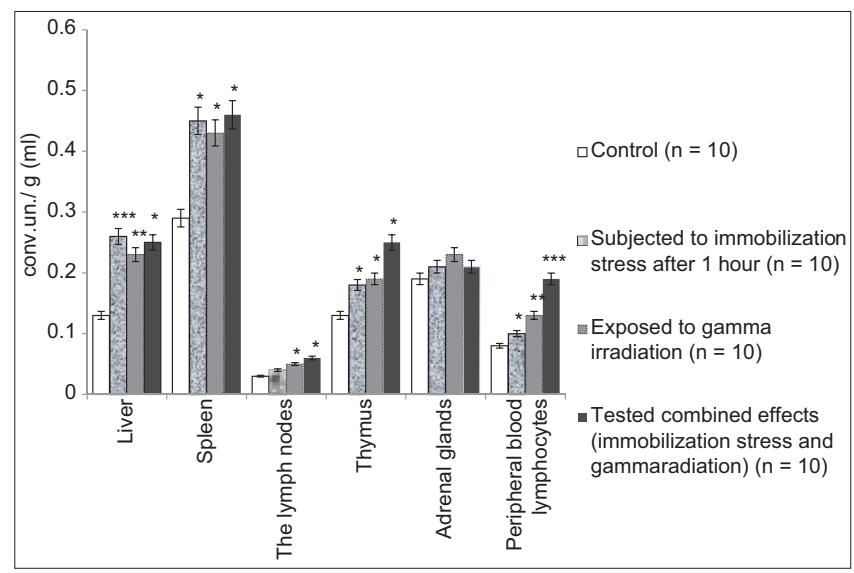

Figure 2: The content of MDA in various objects of research and series in the experiment. The different are statistically significant with the intact group: ${ }^{*}-p<0.05,{ }^{* *}-p<0.01,{ }^{* * *}-p<0.001$

Please reference the figure in the text (Figure 2).

The intensity of LPO processes in the studied objects using MDA in rats exposed to stress, gamma radiation, and their combined effect is presented in Figure 2. In almost all studied groups, the content of the MDA LPO product is significantly higher than in the control group $(p<0.05)$. Under the influence of a stress factor in peripheral blood lymphocytes, the MDA content remained at the level of control values, but there was a slight tendency to increase by 90\% ( $p<0.001)$. Moreover, the response to gamma radiation was marked by an increase in the amount by $62.5 \%$ ( $p<0.01)$. Under stress exposure in the liver homogenate, an increase in the MDA level was noted by 2 times ( $p<0.001)$, with a combined exposure by $92.3 \%$ ( $p<0.05$ ), with an isolated action of gamma radiation, and an increase by $76.92 \%$ ( $p<0.01)$. At the rest of the studied objects, a stable increase in the MDA content was revealed. Thus, in animals, when exposed to a stress factor, the concentration of MDA in the lymph nodes of the small intestine increased insignificantly $(p<0.05)$, when exposed to gamma radiation by $66.6 \%(p<0.01)$, under combined exposure (group IV) by $100 \%$ ( $p<0.001)$. In the thymus homogenate, an increase in the activation of LPO processes was observed, which was expressed in a higher content of MDA in comparison with the control group. The concentration of MDA in group II increased by $38.46 \%$ ( $p<0.05)$, in group III by $46.15 \%$ ( $p<0.05)$, and in group IV by $92.3 \%$ ( $<<0.05)$. A similar dynamics was observed in blood lymphocytes in group II by $25.0 \%$ ( $p<0.05)$, in group III - by 62.5\% ( $<<0.01)$, and in group IV - by $137.5 \%$ ( $p<0.001)$. Under the influence of a stress factor in the adrenal glands, the MDA content remained at the level of control values (Figure 2).

\section{Discussion}

Oxidative stress is one of the important pathogenetic links of many diseases (including occupational ones); in which reactive oxygen species manifest their toxic effect due to their intense generation and depletion of $\mathrm{AO}$ protection.

The studies carried out revealed in all studied groups the activation of LPO processes in objects, which was expressed in a significant increase in the content of MDA and DC. The revealed changes indicate the presence of an imbalance of the oxidative-AO system in the immunocompetent organs in animals exposed to radiation and stress factors, more pronounced in animals exposed to the combined effects of these factors. In animals of the $4^{\text {th }}$ group, the state of oxidative-metabolic processes was characterized by overproduction of LPO products and subsequently by depression of $\mathrm{AO}$ defense. The urgency of continuing research on the combined effects of radiation and stress factors on public health and taking measures to eliminate negative effects on the population seems to be undoubted.

\section{References}

1. Starcevic A, Petricevic S, Djulejic V, Radojicic Z, Starcevic B, Filipovic B. Effects of chronic psychosocial stress on reduction of basal glucocorticoid levels and suppression of glucocorticoid levels following dexamethasone administration in animal model of PTSD. Open Access Maced J Med Sci. 2014;2(1):18-2. Available from: https://www.id-press.eu/mjms/article/view/5. [Last accessed on 2021 Jan 18]. https://doi.org/10.3889/ oamjms.2014.003

2. Yepifantseva $\mathrm{YV}$, Abdrakhmanova MG, Pozdnyakova YV, Semenikhina PS, Belyayev RA, Stupina TA, et al. The level of reactive carbonyl derivatives of proteins, malondialdehyde, and catalase activity in the brain of rats after therapy following chronic unpredictable moderate stress. Open Access Maced $J$ Med Sci. 2020;8(A):691-8. Available from: https://www.id-press. $\mathrm{eu} / \mathrm{mjms} /$ article/view/5396. [Last accessed on $2021 \mathrm{Jan} 18$ ]. https://doi.org/10.3889/oamjms.2020.5396

3. Avrova NF. Biochemical mechanisms of acclimation to changing environmental conditions in vertebrates: The role of lipids. $J$ Evol Biochem Physiol. 1998;34(3):170-80.

4. Zentov NK, Lankin VZ, Menshchikova EB. Oxidative Stress: Biochemical and Pathophysiological Aspects. Moscow: MAIK Nauka/Interperiodica; 2001.

5. Ferenc VP, Prilipko VA. The way of life of the population exposed to radiation exposure as a factor shaping health. Bull Acad Med Sci UUSR. 1991;11:45-6.

6. Kolomiytseva IK, Novoselova EG, Kulagina TP. Study of liver lipids in irradiated animals. Radiobiology. 1986;26:313-7.

7. Kozlov MV, Shishkina LN. Influence of damaging factors of different nature on the composition of liver lipids in mice. Radioecology. 2008;48(3):349-55

8. Kudryashov, Yu B, Goncharenko EN. Stress under the Action of Ionizing Radiation. Moscow, Russian Federation: Yaroshinskaya 
Charitable Foundation; 1996. p. 327-30.

9. Kuzin AM. Stimulating Effect of lonizing Radiation on Biological Processes; 1977.

10. Orekhova NA, Rasina LN. Antioxidant status as a model for the study of the body's radioresistance. In: Physics in Biology and Medicine: Collection of Articles. Proceedings of the 2nd Russian Conference; 2001. p. 120-3.

11. Rozhdestvensky LM. The concept of the biological effect of lowlevel ionizing radiation. Radioecology. 1999;39(1):127-510.

12. Baverstock KF, Stather JM. Low Dose Radiation: Biological Bases of Risk Assessment. Philadelphia: Taylor and Francis; 1989. p. 606

13. Cuttler JM, Cordon HA. Health Effects of Low Level Radiation: When will we Acknowledge the Reality? Vol. 5. New York: Health \& Mental Hygiene; 2007. p. 292-8.

14. Dale W, Gray L, Meredith W. The inactivation of an enzyme (carboxypeptidase) by X-and alpha radiation. Philos Trans $\mathrm{R}$ Soc Lond A. 1949;242:33.
15. Hollivell B, Cutteridge JM. Free Radicals in Biology Vand Medicine. Oxford: University Press; 1999. p. 936.

16. Knizhnikov VA, Shandala NK, Petukhova EV, Pukhovsky NN The role of the subjective factor in the assessment by various groups of the population of the hazard to health of radiation and other risk factors. In: Radioecological, Medical and SocioEconomic Consequences of the Chernobyl Accident. Moscow: Rehabilitation of Territories and Population: Abstracts of Reports; 1995. p. 88.

17. Selye G. Stress without Distress. Moscow: Progress; 1979. p. 126.

18. Surinov BP, Karpova NA. The combined effect of ionizing radiation and stress on antibody genesis in mice. Radioecology. 1996;36(3):359-64.

19. Gavrilov VB, Mishkorudnaya MI. Spectrophotometric determination of the content of lipid hydroperoxides in blood plasma. Lab Work. 1983;3:33-6.

20. Koichubekov BK. Biostatistics: A Training Manual. Almaty: Evero; 2015. p. 152. 